\section{Contamination of bovine, sheep and goat meat with Brucella spp.}

Francesco Casalinuovo, Lucia Ciambrone, Antonio Cacia, Paola Rippa

Institute for Experimental Veterinary Medicine of Southern Italy, Catanzaro, Italy

\section{Abstract}

A study was conducted in order to evaluate the contamination by Brucella spp. of meat from animals slaughtered because they had resulted positive for brucellosis at some time during their life. After slaughter and before delivery to market outlets, swab samples were taken from 307 carcasses of infected animals 40 cattle, 60 sheep and 207 goats. The swabs were subsequently analysed by means of polymerase chain reaction (PCR) tests. In addition, bacteriological tests were carried out on the lymph nodes and internal organs of the same animals. Brucella spp. was detected by means of PCR in 25/307 carcasses (8\%): 1 bovine (2.5\%), 9 sheep (15\%) and 15 goats (7.2\%) and was isolated by means of a cultural method in 136/307 carcasses (44\%). Moreover, additional analysis, performed on lymph nodes from the same carcasses that had proved positive by PCR, allowed highlighting type 3 Brucella abortus in the bovine carcass and type 3 Brucella melitensis in the sheep and goat carcasses. The study shows that cattle, sheep and goats meat of animals slaughtered because they had tested positive for brucellosis may be contaminated by Brucella spp. As this could constitute a real risk of transmission to both butchery personnel and consumers, the meat of animals infected by Brucella spp. should be analysed before being marketed. In this respect, PCR technique performed on swabs proved to be more useful, practical and faster than the traditional bacteriological method.

\section{Introduction}

Brucellosis is a highly contagious zoonosis caused by bacteria of the genus Brucella and is listed in Class B animal epidemics by the World Organization for Animal Health (OIE). The genus has six classic species: $B$. abortus, $B$. melitensis, B. suis, B. canis, B. ovis and $B$. neotomae. Recently, the marine species $B$. ceti, $B$. pinnipedialis, $B$. microti and $B$. inopinata were included in the genus (Foster et al., 2007; Scholz et al., 2008, 2010). The incidence of human brucellosis is estimated by the OIE at
500,000 new cases per year worldwide. However, official statistics is widely acknowledged to be underestimated and, in a considerable number of cases, the origin of the infection is not identified. The majority of human cases worldwide is attributed to B. melitensis (Pappas et al., 2005). In general, $B$. melitensis and $B$. suis are more virulent in humans than $B$. abortus or $B$. canis (WHO, 2006). Other species can cause infection in humans, but only rarely (Diaz Aparicio, 2013). The disease is more prevalent in western parts of Asia, India, Middle Eastern, Southern European and Latin American countries. The transmission of brucella infection and its prevalence in a region depend on several factors, such as dietary habits, methods of processing milk and milk products, social customs, husbandry practices, climatic conditions, socioeconomic status and environmental hygiene (Mantur and Amarnath, 2008). As the infectious dose is very low, infections are an occupational risk for farmers, veterinarians, abattoir workers (Schneider et al., 2013), laboratory personnel and others who work with animals and consume their products (Pepin et al., 1997). Human brucellosis is transmitted by inhalation, animal contact and the consumption of dairy products and undercooked meat products. The consumption of traditional dishes, such as raw liver, can cause human infection (Malik, 1997). Muscle tissue generally contains a small number of organisms. However, it has been estimated that even 10-100 microorganisms are sufficient to cause the disease in humans (Pappas et al., 2006). Thus, contaminated meat and meat products could represent a source of infection, especially if they come from animals slaughtered during the acute phase of the disease (FAONHO, 1986) and if they are consumed raw or undercooked. The handling and preparation of infected meat and offal may give rise to the contamination of other foodstuffs and kitchen utensils (WHO/CDS/EPR/2006.7; WHO, 2006). Tests carried out in the US on the carcasses of bovine and swine that were slaughtered because infected revealed that $1.2 \%$ of the bovine carcasses and $3.5 \%$ of the swine carcasses were contaminated by Brucella spp. (Sadler, 1960). In a similar study conducted in India on 100 carcasses of goats, two of the 700 neck muscle samples analysed tested positive for Brucella melitensis (Randhawa and Karla, 1970). Other studies have shown that the offal of slaughtered ruminants constitutes a risk for transmission of the infection (Fatma and Mahdey, 2010; Sekulovski, 2008). In order to evaluate the prevalence of contamination of meats and to assess the risk of infection for consumers and professionally exposed workers, an investigation on 307 carcasses of bovines, sheep and goats that were slaughtered because they had resulted positive on serological testing for Brucella spp. was performed. The study was carried out within the framework of the national programmes for the
Correspondence: Francesco Casalinuovo, Institute for Experimental Veterinary Medicine of Southern Italy, viale Crotone snc, 88100 Catanzaro, Italy.

Tel: +39.0961.737763 - Fax: +39.0961.738088

E-mail: francesco.casalinuovo@cert.izsmportici.it

Key words: Brucella spp.; Food safety; Meat; Polymerase chain reaction.

Conflict of interest: the authors declare no potential conflict of interest.

Received for publication: 5 April 2016. Revision received: 18 April 2016.

Accepted for publication: 18 April 2016.

This work is licensed under a Creative Commons Attribution-NonCommercial 4.0 International License (CC BY-NC 4.0).

(C) Copyright F. Casalinuovo et al., 2016 Licensee PAGEPress, Italy

Italian Journal of Food Safety 2016; 5:1913 doi:10.4081/ijfs.2016.5913

eradication and monitoring of animal diseases and the prevention of zoonoses in Italy, approved by Decisions 2011/807/UE and 2012/761/UE of the European Commission (2011, 2012).

\section{Materials and Methods}

The study lasted 12 months and was carried out in 10 abattoirs in southern Italy, where brucellosis infection is still widespread on cattle, sheep and goat farms. After slaughter, swab samples were taken from 307 carcasses: 40 cattle, 60 sheep and 207 goats. These animals came from 24 different farms and were slaughtered because they had proved positive on serological tests for Brucella spp. In previous studies (Randhawa and Karla, 1970; Fatma and Mahdey, 2010) Brucella spp. contamination of the carcasses of slaughtered animals had been evaluated by means of microbiological tests carried out on samples of muscle or organ tissue. In the present study, swab samples were taken in accordance with the procedure indicated by the Decision of the European Commission (2001): duplicate samples were taken by means of swabs - both dry and moistened in a sterile aqueous solution - which were wiped over the external and internal surfaces of the carcasses immediately after slaughter and before storage in refrigerators. A total of 608 swab samples were taken; no transport medium was deemed necessary, as the samples were promptly consigned to the laboratory, where they underwent polymerase chain reaction (PCR) analysis for Brucella spp. in accordance with the following procedure. 
For DNA extraction, a commercially available kit (QIAamp DNA Mini Kit; Qiagen, Valencia, CA, USA) was used according to the protocol described for the swab matrix. Amplification was carried out by means of a nested PCR technique, based on a published protocol (Romero et al., 1995; Romero and Lopez-Goni, 1999; Tantillo et al., 2001, 2003), involving two successive amplification steps. The second step utilised a pair of oligonucleotides that are internal to those used in the first step and produce a smaller fragment; they prove functional only if the result of the first PCR is specific. The first amplification step used the primer pairs F4 (5'-TCGAGCGCCCGCAAGGGTGAGCGG-3') and R2 (5'-AACCATAGTGTCTCCACTAACC-3') allowing an amplification product of $905 \mathrm{bp}$. In the second step of PCR, the primer pairs R0 (5'-TAGCTAGTTGGTGGGGTAAAGGC-3') and R1 (5'CAGGCTTGCGCCCATTGTCC-3') were used allowing an amplification product of $144 \mathrm{bp}$. To prepare the reaction mixture for the first PCR, $12.5 \mu \mathrm{L}$ of a commercially available PCR master mix (PCR master mix; Promega Corp., Madison, WI, USA) was used at a $1 \mathrm{X}$ concentration for each sample. The reaction mixture contains 50 units/mL of Taq polymerase, 400 $\mathrm{mM}$ of dATP, dGTP, dCTP, DTTP and $3 \mathrm{mM}$ of $\mathrm{MgCl}_{2}$. To the reaction mixture, $0.5 \mu \mathrm{L}$ of each primer - F4 and R2 at a concentration of 0.2 $\mu \mathrm{M}$ - and $6.5 \mu \mathrm{L}$ of $\mathrm{H}_{2} \mathrm{O}$ were added, with a final reaction volume of $25 \mu \mathrm{L}$. As a positive control in PCR, we used a type-3 Brucella melitensis biovar saved in our laboratory. The negative control was made up only of master mix and water.

To prepare the reaction mixture for the second PCR, the same procedure was carried out, with primers $\mathrm{R} 1$ and $\mathrm{R} 0$. The thermal profile of the first PCR involved an initial denaturation at $95^{\circ} \mathrm{C}$ for 4 ' followed by 35 cycles of denaturation (at $94^{\circ} \mathrm{C}$ for $1^{\prime}$ ), annealing (at $54^{\circ} \mathrm{C}$ for $\left.1^{\prime}\right)$ and extension (at $72^{\circ} \mathrm{C}$ for $1^{\prime}$ ) and a final extension at $72^{\circ} \mathrm{C}$ for 7 '. The thermal profile of the second PCR was the same as the first one except for the cycle number that consisted of 30 cycles in the second PCR. In accordance with Italian law and with the aim of eradicating brucellosis in cattle, sheep and goats, the carcasses of infected animals may be freely marketed if the outcome of post-slaughter examination is favourable, while all the internal organs and the udders must be destroyed. Parts of these organs were therefore removed and subjected to culture tests for the bacteriological identification and typing of Brucella spp. by means of the technique described in the Manual of the Office International des Epizooties, ch. 2.4.3 2009 lett. B (OIE, 2015). This involves: streaking on brucella agar medium added with a selective supplement and horse serum; incubation at $37^{\circ} \mathrm{C}$ in an atmosphere enriched with $5-10 \% \mathrm{CO}_{2}$; and observa- tion for up to 10 days. Subsequent species typing of the isolated strains was carried out at the National Reference Centre for Brucellosis in Teramo (Italy) by means of the PCR-restriction fragment length polymorphism technique, in accordance with the procedure prescribed in Vol. 1, Part. 2, Sect. 2.4 Ch. 2.4.3. of the OIE Manual (OIE, 2015).

\section{Results}

The biomolecular tests revealed the presence of Brucella spp. in 25/307 carcasses (8\%): 1 bovine carcass (2.5\%) of a 9-year-old cow; 9 carcasses of sheep (15\%) aged between 18 months and 5 years, all from the same farm; and 15 carcasses of goats (7.2\%) aged between 12 months and 6 years and coming from 5 different farms (Figure 1). The 25 carcasses found to be contaminated with Brucella spp. belonged to 25 animals slaughtered in 6 different slaughterhouses. The bacteriological tests carried out on the organs of all 307 animals examined allowed isolating Brucella spp. in 136/307 cases, i.e. $44 \%$. The typing analysis allows detecting type 3 Brucella abortus in the cattle organs, and type 3 Brucella melitensis in the sheep and goats organs. The organs, specifically the lymph nodes, from all the carcasses that had tested positive on PCR on swabs, also proved positive on bacteriological testing for type 3 Brucella abortus (the bovine carcass) and for type 3 Brucella melitensis (the sheep and goat carcasses).

\section{Discussion}

The results obtained show that the carcasses (i.e., the meat) of animals slaughtered due to Brucella spp. infection may also be contaminated by the same infective agent. This situation is the same as that seen in the case of other pathogens, like Salmonella spp., for which specific laboratory tests are prescribed and measures have to be taken. In the present study, the percentage of meats that proved to be contaminated was far higher than in the studies quoted above (Sandler, 1960; Randhawa and Karla, 1970). Contamination by Brucella spp. was detected in a higher percentage of sheep carcasses than cattle or goat carcasses, while the bacteriological tests conducted on the organs detected the highest percentage of contamination among goats. The only Brucella serotypes isolated from the organs were type 3 Brucella abortus in cattle and type 3 Brucella melitensis in sheep and goats. These are the only serotypes that have been isolated in recent years in the geographical area considered (Casalinuovo et al., 2011; De

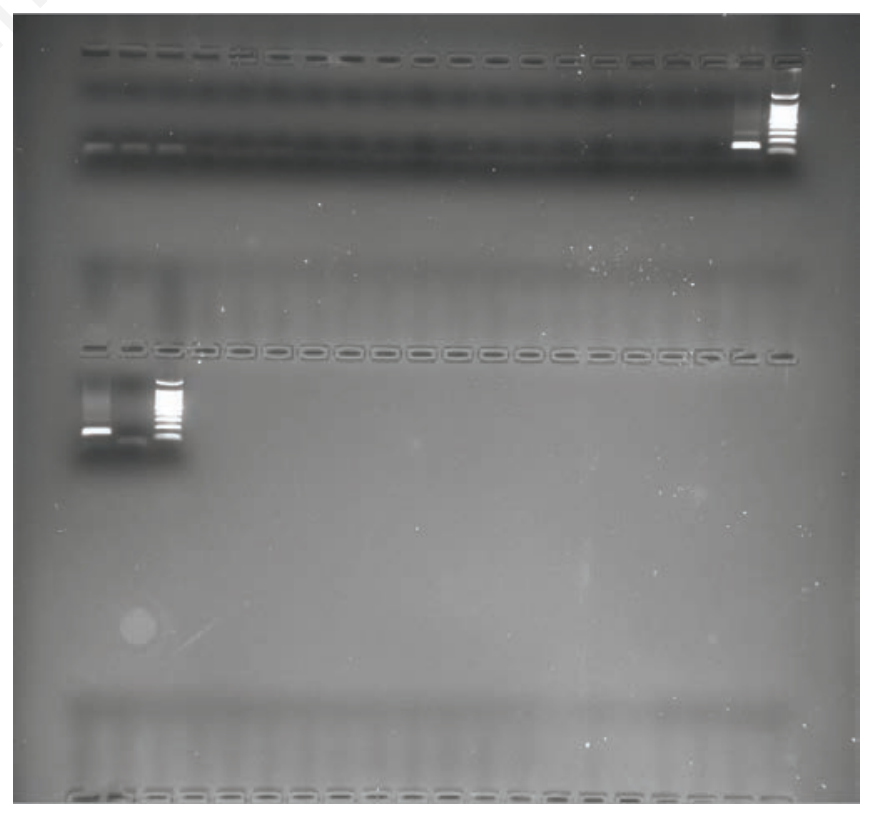

Figure 1. Polymerase chain reaction analysis for Brucella spp. Amplification product derived from the analysis of 19 swabs: $10 \mu \mathrm{L}$ of each reaction mixture was separated by means of $2 \%$ agarose gel, observed under ultraviolet light and photographed. A $100 \mathrm{bp}$ marker was used as a reference. Positive and negative controls were loaded in the last two wells of the gel, while the presence of a positive sample (144 bp) can be noted in the $19^{\text {th }}$ well. 
Massis et al., 2014). The handling of the carcass entrails in the slaughterhouse has surely caused contamination. Thus, the environments and facilities of slaughterhouses may also be severely contaminated, thereby constituting a risk of contagion for staff involved in butchery and meat handling, and a risk of contamination of the carcasses of other animals that are not infected by brucellosis. Indeed, the positivity of the carcasses involved $6 / 10$ slaughterhouses.

Our samples were taken at the end of the butchery process, when the carcasses were ready for storage in refrigerators or delivery to retail outlets. This means that each contaminated carcass could in turn contaminate equipment and utensils and other meats or foodstuffs. Consequently, even in domestic kitchens, contamination could further involve other equipment, utensils and food products. Indeed, as Brucella spp. survives well at the temperatures reached by refrigerators or freezers, other refrigerated or frozen foods may become contaminated. Thus, all meat products must be thoroughly cooked before being eaten.

PCR testing of swab samples taken from the carcasses of animals that had tested positive for Brucella proved to be useful. This practice could be applied systematically, since this noninvasive sampling technique does not damage commercial meat cuts, is economically advantageous, and requires far less time (24-48 h) than detection by means of culture media. Carcasses that resulted positive for PCR might be sequestered and potentially submitted to different confirmation tests.

\section{Conclusions}

Annex I, section IV, chapter IX, F, of Regulation (CE) $\mathrm{N}^{\circ}$. 854/2004 (European Commission, 2004) deals with what should be done with meat from infected animals, and lays down preventive measures to be taken with regard to the specific risks of brucellosis. Indeed, the Regulation requires that animals proving positive or uncertain for brucellosis have to be slaughtered separately, and that precautions have to be taken to avoid the risk of contaminating other carcasses, the butchery process and the abattoir staff. The udders, genital organs and blood of such animals are classified as unfit for human consumption, while their meat can be freely marketed. Only if postmortem examination reveals lesions attributable to acute infection by Brucella spp. must their meat be declared unfit for consumption and destroyed. Otherwise, the meat of these animals, just like the meat of healthy animals, is allowed to enter the food chain. These measures are justified by the need to avoid the destruction of large amounts of meat, which is a valuable food source. Nevertheless, the results of the present study show that the carcasses, and consequently the meat, of animals positive for brucellosis may be contaminated by Brucella spp. This means that consumers may be exposed to the risk of infection, so they should be sufficiently informed with regard to the origin of the meat at the time of purchase.

\section{References}

Casalinuovo F, Musarella R, Mungo V, Guarino A, 2011. [Circolazione di biovarianti di Brucella spp. in aree endemiche]. [In Italian]. In: Casalinuovo F, Musarella R, Rippa P, Mungo V, Guarino A, eds. Proceedings of the 6th Workshop of Veterinary Epidemiology, 2011 Dec 1-2, Orvieto, Italy.

De Massis F, Zilli K, Ancora M, Di Donato G, Scacchia M, Di Giannatale E, 2014. Update about typing of Brucella field strains isolated from livestock and wildlife populations in Italy, 2007-2012. In: Brucellosis 2014, Proceedings of the International Research Conference, 2014 Sep 9-12, Berlin, Germany. Bundesinstitut für Risikobewertung, Berlin, Germany, p. 185. Diaz Aparicio E, 2013. Epidemiology of brucellosis in domestic animals caused by Brucella melitensis, Brucella suis and Brucella abortus. Rev Sci Tech 32:53-60.

European Commission, 2001. Commission decision of 8 June 2001 laying down rules for the regular checks on the general hygiene carried out by the operators in establishments according to Directive 64/433/EEC on health conditions for the production and marketing of fresh meat and Directive 71/118/EEC on health problems affecting the production and placing on the market of fresh poultry meat, 2001/471/EC. In: Official Journal, L 165, 21/06/2001, pp. 48-53.

European Commission 2004. Commission regulation (OJ L226, p 83, 29/04/2004) of the European Parliament and of the Council of 29 April 2004 laying down specific rules for the organisation of official controls on products of animal origin intended for human consumption, 854/2004/EC. In: Official Journal, L 226/83, 25.6.2004.

European Commission, 2011. Commission decision of 5 December 2011 amending Annex V to Council Regulation (EC) No $1342 / 2007$ as regards the quantitative limits of certain steel products from the Russian Federation, 2011/807/UE. In: Official Journal, L 322/1, 6.12.2011.

European Commission, 2012. Commission decision of of 25 July 2013 approving cer- tain amended programmes for the eradication, control and monitoring of animal diseases and zoonoses for the year 2013 and amending Implementing Decision 2012/761/EU as regards the Union financial contribution for certain programmes approved by that Decision, 2012/761/UE. In: Official Journal, L 202/30, 27.7.2013.

Fatma HM, Mahdey A, 2010. Incidence of Brucella species in slaughtered food animals and its edible offal at Beni-suef, Egypt. Global Veterinaria 5:248-54.

FAO/WHO, 1986. Sixth report of the joint FAO/WHO Expert Committee on brucellosis. World Health Organization, Geneva, Switzerland.

Foster G, Osterman BS, Godfroid J, Jacques I, Cloeckaert A, 2007. Brucella ceti sp. nov and Brucella pinnipedialis sp. nov. for Brucella strains with cetaceans and seals as their preferred hosts. Int J Syst Evol Micr 57:2688-93.

Malik GM, 1997. A clinical study of brucellosis in adults in the Asir region of southern Saudi Arabia. Am J Trop Med Hyg 56:3757.

Mantur BG, Amarnath SK, 2008. Brucellosis in India: a review. J Bioscience 33:539-47.

OIE, 2015. Manual of diagnostic tests and vaccines for terrestrial animals 2015. Bovine brucellosis. World Organization for Animal Health, Paris, France.

Pappas G, Akritidis N, Bosilkovski M, Tsianos E, 2005. Brucellosis. New Engl J Med 352:2325-36.

Pappas G, Panagopoulou P, Christou L, Akritidis N, 2006. Brucella as a biological weapon. Cell Mol Life Sci 63:2229-36.

Pepin M, Russo P, Pardon P, 1997. Public health hazards from small ruminant meat products in Europe. Rev Sci Tech 16:415-25.

Randhawa AS, Karla DS, 1970. Human pathogens from goat meat. Brucellae. Indian J Med Res 58:181-6.

Romero C, Gamazo C, Pardo M, Lopez-Goni I, 1995. Specific detection of Brucella DNA by PCR. J Clin Microbiol 33:615-7.

Romero C, Lopez-Goni I, 1999. Improved method for purificaion of bacterial DNA from bovine milk for detection of Brucella spp. by PCR. Appl Environ Microb 65:3735-7.

Sadler WW, 1960. Present evidence on the role of meat in the epidemiology of human brucellosis. Am J Public Health 50:504-14.

Schnéeider RC, Santos MD, Lunardi M, Benetti AH, Camargo LM, Freitas SH, Negreiro RL, Costa DS, 2013. Prevalence of brucellosis and risk factors associated with its transmission to slaughterhouse employees in the Cuiaba metropolitan area in the state of Mato Grosso. Cienc Agr 34:2367-74.

Scholz HC, Hubalek Z, Sedlacek I, Vergnaud G, Tomaso H, Al Dahouk S, Melzer F, Kampfer P, Neubauer H, Cloeckaert A, Maquart M, 
Zygmunt MS, Whatmore AM, Falsen E, Bahn P, Göllner C, Pfeffer M, Huber B, Busse HJ, Nöckler K, 2008. Brucella microti sp. nov., isolated from the common vole Microtus arvalis. Int $\mathrm{J}$ Syst Evol Micr 58:375-82.

Scholz HC, Nockler K, Gollner C, Bahn P, Vergnaud G, Tomaso H, Al Dahouk S, Kampfer P, Cloeckaert A, Maquart M, Zygmunt MS, Whatmore AM, Pfeffer M, Huber B, Busse HJ, De BK, 2010. Brucella inopinata sp. nov., isolated from a breast implant infection. Int $\mathbf{J}$ Syst Evol Micr 60:801-8.

Sekuloski P, 2008. Znaaj Brucella melitensis za bezbednost hrane. Vet Glasnik 62:289-99.

Tantillo G, Di Pinto A, Buonavoglia C, 2003. Detection of Brucella spp in soft cheese by semi-nested polymerase chain reaction. J Dairy Res 70:245-7.

Tantillo G, Di Pinto A, Vergara A, Buonavoglia C, 2001. Polymerase chain reaction for detection of Brucella spp. in milk and cheese. J Food Protect 64:164-7.

WHO, 2006. Brucellosis in human and animals.

World Health Organization, Geneva, Switzerland. Available from www.who.int/csr/resources/publications/B rucellosis.pdf 